\section{National Stroke Awareness Month — May 2017}

May is National Stroke Awareness Month, an observance that highlights the importance of knowing the signs and symptoms of stroke and encourages persons to act FAST (Face drooping, Arm weakness, Speech difficulty, Time to call 9-1-1) if someone is having a stroke. Stroke is the fifth leading cause of death in the United States and a leading cause of severe disability $(1,2)$. In the United States, one person dies from stroke approximately every 4 minutes (2).

Stroke is preventable and largely treatable. Yet, a recent $\mathrm{CDC}$ report notes that the age-adjusted death rate for stroke slightly increased from 36.5 deaths per 100,000 persons in the United States in 2014 to 37.6 in 2015 (1). Approximately $60 \%$ of persons who die from stroke are women, and women tend to have worse functional outcomes after experiencing a stroke (3). CDC urges everyone to learn the warning signs of stroke and take action to reduce their risk. Living a healthy lifestyle (e.g., being physically active, eating more fruits and vegetables and foods low in sodium and salt, maintaining a healthy weight, and avoiding smoking) can reduce the chances of having a stroke. Properly managing certain medical conditions (e.g., high blood pressure, high cholesterol, heart disease, and diabetes) also can lower the risk.

CDC promotes stroke prevention through several initiatives. The Million Hearts initiative, co-led by CDC and the Centers for Medicare \& Medicaid Services, works to prevent stroke. The Paul Coverdell National Acute Stroke Program (https:// www.cdc.gov/dhdsp/programs/stroke_registry.htm) funds state health departments to collect and use data to ensure highquality, statewide systems of care to treat stroke. Additional information regarding stroke prevention is available at https:// www.cdc.gov/stroke/.

\section{References}

1. Xu JQ, Murphy SL, Kochanek KD, Arias E. Mortality in the United States, 2015. NCHS data brief, no 267. Hyattsville, MD: US Department of Health and Human Services, CDC, National Center for Health Statistics; 2016.

2. Mozaffarian D, Benjamin EJ, Go AS, et al. Heart disease and stroke statistics-2015 update: a report from the American Heart Association. Circulation 2015;131:e29-322. https://doi.org/10.1161/ CIR.0000000000000152

3. George MC, Fischer L, Koroshetz W, et al. CDC grand rounds: public health strategies to prevent and treat strokes. MMWR Morb Mortal Wkly Rep 2017;66:479-81.

\section{Community Preventive Services Task Force Recommendation for Family-Based Interventions to Increase Physical Activity}

The Community Preventive Services Task Force recently posted new information on its website: "Physical Activity: Family-Based Interventions." This information is available at https://www.thecommunityguide.org/findings/ physical-activity-family-based-interventions.

Established in 1996 by the U.S. Department of Health and Human Services, the task force is an independent, nonfederal, panel of public health and prevention experts whose members are appointed by the director of CDC. The task force provides information for a wide range of persons who make decisions about programs, services, and other interventions to improve population health. Although CDC provides administrative, scientific, and technical support for the task force, the recommendations developed are those of the task force and do not undergo review or approval by CDC. 